\title{
Maximal expiratory flows generated by rapid chest compression following end-inspiratory occlusion or expiratory clamping in young children
}

\author{
E. Kerem**, J. Reisman*, S. Gaston*, \\ H. Levison*, A.C. Bryan*
}

Maximal expiratory flows generated by rapid chest compression following end-expiratory occlusion or expiratory clamping in young children. E. Kerem, J. Reisman, S. Gaston, H. Levinson, A.C. Bryan. CERS Journals Ltd 1995.

ABSTRACT: Partial forced expiratory flow-volume curves obtained by the rapid chest compression technique are being widely used to assess pulmonary function in infants and young children. The aim of this study is to assess whether in this age group flow limitation is achieved with the partial forced expiratory flow-volume curve with rapid chest compression.

In eight infants and young children sedated with chloral hydrate, flow-volume curves were obtained by regular rapid chest compression technique, end-inspiratory airway occlusion prior to rapid chest compression, and expiratory clamping prior to rapid chest compression. In each technique, beginning with a cuff pressure of $20 \mathrm{cmH}_{2} \mathrm{O}$, the cuff pressure was increased by $10 \mathrm{cmH}_{2} \mathrm{O}$ increments until the compression pressure reached $90 \mathrm{cmH}_{2} \mathrm{O}$. Maximal flow-volume curves were generated by each technique.

End-inspiratory occlusion prior to rapid chest compression caused higher flows over the entire phase of expiration than the regular rapid chest compression. This increase could be observed over the entire phase of expiration. Forced expiratory flow at $50 \%$ and at $75 \%$ of vital capacity (V50 and V75) with regular rapid chest compression were $207 \pm 44 \mathrm{ml} \cdot \mathrm{s}^{-1}$ (mean $\left.\pm \mathrm{sD}\right)$ and $138 \pm 59 \mathrm{ml} \cdot \mathrm{sec}^{-1}$, respectively. When end-inspiratory occlusion preceded rapid chest compression, $\dot{\mathbf{V} 50}$ and $\mathbf{V}_{75}$ increased to $283 \pm 114$ and $206 \pm 61 \mathrm{ml} \cdot \mathrm{sec}^{-1}$ respectively, with a mean increase in $\dot{\mathrm{V}} 50$ of $34 \%$ and in $\dot{V} 75$ of $31 \%$. When expiratory clamping preceded the compression, even higher expiratory flows resulted. $\dot{V} 50$ increased to $227 \pm 171 \mathrm{ml} \cdot \mathrm{sec}^{-1}$ and $\dot{V} 75$ to $264 \pm 104 \mathrm{ml} \cdot \mathrm{sec}^{-1}$ with a mean increase in $\mathrm{V} 50 \mathrm{of} 53 \%$ and in $\mathrm{V} 75 \mathrm{of} 55 \%$, compared to regular rapid chest compression. Expiratory time corrected for expiratory volume shortened significantly from $12.8 \pm 7.4 \mathrm{~ms} \cdot \mathrm{ml}^{-1}$ in regular rapid chest compression to $10.2 \pm 5.8 \mathrm{~ms}^{\prime} \mathrm{ml}^{-1}$ with end-inspiratory occlusion prior to rapid chest compression, and to $7.2 \pm 3.6 \mathrm{~ms} \cdot \mathrm{ml}^{-1}$ when expiratory clamping preceded rapid chest compression.

This study suggests that the flow limitation is not always reached by the traditional rapid chest compression method.

Eur Respir J., 1995; 8, 93-98.

The partial forced expiratory flow-volume curves obtained by the rapid chest compression technique (RCT) first introduced by ADLER and WOHL [1], have been widely used to assess pulmonary function in infants and young children. The technique has also been utilized to study the pathophysiology of various lung diseases in infancy, and to assess their response to different therapeutic strategies [2-9]. In sleeping sedated infants, external pressure is applied around the chest and the abdomen to simulate that pressure produced by activation of respiratory muscles in forced expiration. The applied pressure is transmitted to the surface of the infant, and, thus, across the chest and abdominal walls. Ideally, with this technique, the chest wall musculature is relaxed, and the infant is not resisting the action of the applied pressure. The
*Division of Respiratory Medicine and Dept. of Respiratory Physiology, The Hospital For Sick Children, Toronto, Canada. **Pulmonary and Cystic Fibrosis Clinic, Shaare Zedek Medical Center, Jerusalem, Israel.

Correspondence: E. Kerem Pulmonary and Cystic Fibrosis Clinic Shaare Zedek Medical Center Jerusalem

Israel 91031

Keywords: End-inspiratory occlusion expiratory clamping flow-volume curves infant

lung mechanics pulmonary function

Received: December 281993 Accepted after revision September 24 1994 compression pressure is gradually increased, until a point is reached such that further increases in the compression pressure are not accompanied by an increase in the airflow. It was hypothasized that this maximal flow represents flow limitation.

Whilst performing the RCT on infants, we often observed contraction of the sternocleidomastoid muscle and occasionally heard an audible grunt during the squeeze. This suggested that expiratory braking might be occurring, due to active inspiratory muscle contraction and laryngeal adduction. Other investigators have previously suggested that braking is present on the basis of a fall in oesophageal pressure immediately after the squeeze [10, 11]. Several other important unanswered questions concerning RCT methodology have been previously raised 
[12]. One critical question deals with the issue of whether or not flow limitation is actually reached. To demonstrate the presence of flow limitation, isovolume flowpressure curves have to be produced utilizing pleural pressure measurements [13].

Infants and young children have a powerful HeringBreuer reflex, and will normally relax their respiratory muscles when their airway is occluded at a lung volume above the end-expiratory volume [14]. Expiratory clamping, as described by GRUNSTEIN et al. [5], enables one to increase lung volume to approach total lung capacity (TLC); and, thus, possibly increase the magnitude and duration of the Hering-Breuer reflex. The resulting elastic recoil pressure of the lung is increased at this higher volume, and thus adds higher elastic recoil to the external compression pressure supplied by RCT $[16,17]$.

The aim of this study was to compare the expiratory flow achieved by RCT to that achieved after relaxing the respiratory muscles by end-inspiratory occlusion prior to RCT with and without expiratory clamping.

\section{Material and methods}

Eight infants and young children aged 2-40 months participated in this study. Three children suffered from chronic interstitial pneumonitis [18] and five from cystic fibrosis. The clinical details of the patients are shown in table 1 . All patients were clinically stable at the time of the study and did not have any signs of acute respiratory tract infection. Studies were performed under sedation with $70-100 \mathrm{mg} \cdot \mathrm{kg}^{-1}$ of chloral hydrate given orally. The study was performed with the approval of the Human Subjects Review Committee of the Hospital for Sick Children, and consent was given by the parents for each subject.

\section{Equipment}

Forced expiration was achieved using a pressurecontrolled reservoir connected to an inflatable plastic cuff encircling the chest wall and abdomen. The outer cover of the cuff was nondistensible. Flow was measured with a Fleisch No. 1 pneumotachograph connected to a Validyne DM45 differential pressure transducer $\left( \pm 2 \mathrm{cmH}_{2} \mathrm{O}\right)$ (Validyne Co., Northbridge, CA, USA),

Table 1. - Clinical details of the patients studied

\begin{tabular}{lcccc}
\hline $\begin{array}{c}\text { Pat } \\
\text { No. }\end{array}$ & $\begin{array}{c}\text { Age } \\
\text { months }\end{array}$ & $\begin{array}{c}\text { Weight } \\
\mathrm{kg}\end{array}$ & $\begin{array}{c}\text { Length } \\
\mathrm{cm}\end{array}$ & Diagnosis \\
\hline 1 & 34 & 13.0 & 95 & $\mathrm{CIP}$ \\
2 & 5 & 4.18 & 61 & $\mathrm{CF}$ \\
3 & 8 & 8.1 & 71 & $\mathrm{CF}$ \\
4 & 40 & 14.8 & 105 & $\mathrm{CIP}$ \\
5 & 6 & 4.53 & 61.5 & $\mathrm{CF}$ \\
6 & 2 & 4.48 & 58 & $\mathrm{CF}$ \\
7 & 21 & 11.6 & 83 & CIP \\
8 & 7.5 & 6.62 & 66 & $\mathrm{CF}$ \\
\hline
\end{tabular}

Pat: Patient; CIP: chronic interstitial pneumonitis; CF: cystic fibrosis. linear flow up to $1 l \cdot \mathrm{s}^{-1}$. The pneumotachograph was attached to a face mask placed over the patient's mouth and nose, with special care to avoid compression of the nose. Air leaks were prevented by placement of a rim of silicone putty around the edge of the face mask. The patients were studied in the supine position, with the shoulders slightly elevated and neck extended. Volume was obtained by electrical integration of the flow signal. Airway pressure was measured using a Validyne OP45 differential pressure transducer $\left( \pm 2.5 \mathrm{cmH}_{2} \mathrm{O}\right)$ (Validyne, Northbridge, CA, USA). Pressure and volume were recorded on a 4-channel Graphtec Linear recorder mark VI WR 3101 chart recorder (Graphtec Co., Tokyo, Japan). For four patients, pressure and flow were also recorded on a Honeywell 5600 tape recorder (Honeywell, Denver, CO, USA).

\section{Procedure}

Studies were commenced with a cuff inflation pressure of $20 \mathrm{cmH}_{2} \mathrm{O}$. The cuff was rapidly inflated at endinspiration, and flow-volume curves were generated. A pressure transducer was placed in the inner surface of the cuff to ensure that the pressure applied remain constant throughout expiration. This was repeated for a minimum of five different breaths at least $30 \mathrm{~s}$ apart. When similar flow curves were obtained, the cuff pressure was increased by increments of $10 \mathrm{cmH}_{2} \mathrm{O}$ until the compression pressure reached $90 \mathrm{cmH}_{2} \mathrm{O}$. The study was repeated after manually occluding the airways at the end of inspiration for approximately $500 \mathrm{~ms}$ prior to the compression. Relaxation of the respiratory muscles was confirmed by a pressure plateau. Chest compression was initiated during the pressure plateau, with simultaneous release of the occlusion. This procedure was repeated several times for each compression pressure. Finally, a one-way valve system was attached to the pneumotachograph to allow inspiration only. With expiratory occlusion, the infant continued to inspire through the inspiratory port which closed on expiration. This resuled in a stepwise increase in lung volume, and, frequently, in longer pressure plateaus between breaths. After 3-5 successive inspirations, the chest was compressed during a pressure plateau while the occlusion was released. This manoeuvre was repeated several times at all compression pressures. Volume was continuously measured throughout the study. Special care was taken to note the volume recruitment occurring during this procedure, and each manoeuvre was commenced only after the return of lung volume to baseline as indicated on the volume recorder. Figure 1 demonstrates an example of the plateau applied pressure achieved, together with the flow volume tracings obtained for the three different manoeuvres.

\section{Data analysis}

The curves were digitized using a Hewlett-Packard 911A Graphics Tablet (Hewlett-Packard, Cupertino, CA, USA) and superimposed using the end-expiratory 


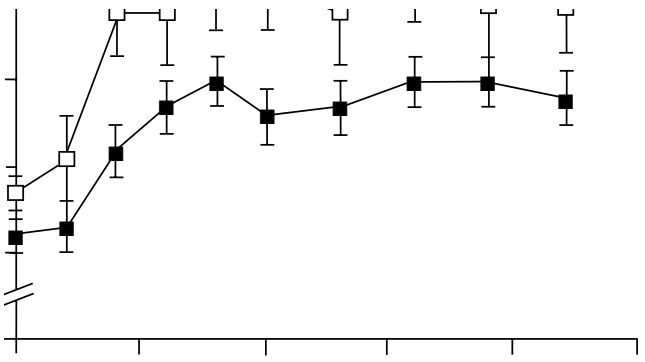

Fig. 1. - Example of volume time and pressure time tracings. a) RCT marked by arrow; b) RCT preceded by end-expiratory occlusion; c) RCT preceded by expiratory clamping. RCT: rapid chest compression technique; Vт: tidal volume; Pao: pressure at airway opening. Dashed line represents basal end-expiratory volume.

volume to anchor them one to the other. We chose the curve after which further increase in compression pressure did not cause increase in flow along the second half of expiration as the maximal flow curve. The curve that resulted in the maximal flow at the minirnal compression pressure was chosen from each of the three techniques. Conventionally, maximum flow has been measured at functional residual capacity (FRC), either from measured FRC, or, more commonly, from the end-expira tory position of the previous tidal breaths. The endexpiratory volume during tidal breathing in sleeping infants, and in respiratory-compromised young children is often very unstable $[19,20]$. Furthermore, it is generally assumed that the RCT compresses the lung to the residual volume (RV) [1, 21, 22]. Thus, RV was considered the appropriate point at which to anchor the curves. The points at which 50 and $75 \%$ of expired volume resulted with the regular RCT curve were identified ( $\dot{V}_{50}$ and $\left.\dot{V}_{75}\right)$. The flows for the three superimposed curves were measured at these points by drawing a vertical line and digitizing the points where the vertical line intersected the curves (fig. 2).

The end-expiratory volume after a compression may vary depending on the volume history; usually, it is lower after end-inspiratory occlusion and higher after stacking, and the volume history of the various curves could differ from breath to breath. Another way to

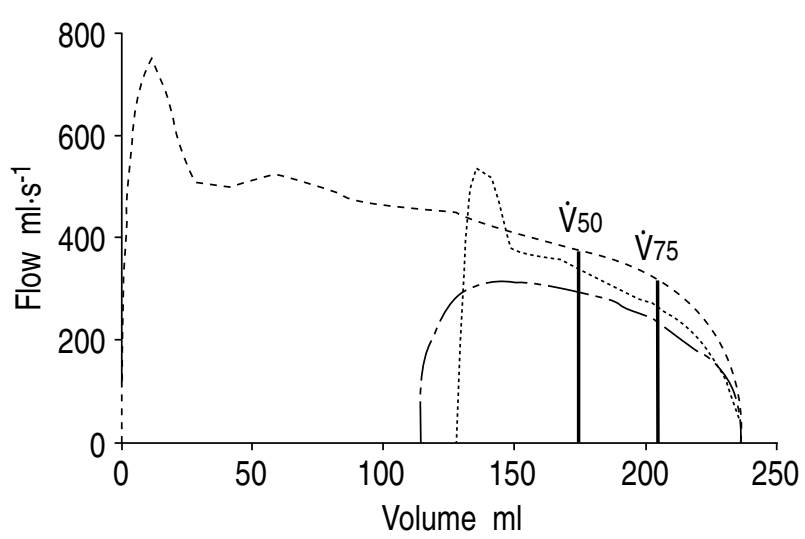

Fig. 2. - Flow-volume curves obtained by the three different tecniques anchored at the the end-expiratory points. Vertical lines represent $\dot{V}_{50}$ and $\dot{V}_{75}$ achieved with RCT.- : RCT; - : $_{-}$ end-inspiratory occlusion prior to RCT; : : expiratory clamping prior to RCT. RCT: rapid chest compression technique; $\dot{V}_{50}$ and V70: forced expiratory flow at $50 \%$ and $70 \%$ of vital capacity.

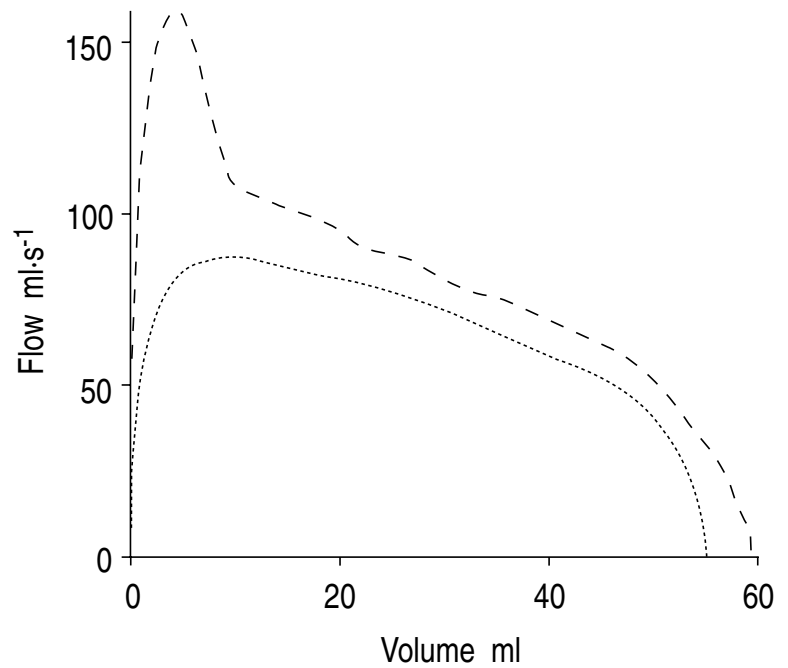

Fig. 3. - Flow-volume curves obtained by RCT with and without end-inspiratory inclusion, anchored at the end-inspiratory points. -----: RCT; __ : end-inspiratory occlusion prior to RCT.

compare the curves derived from the conventional RCT and end-inspiratory occlusion techniques is to assume that end-inspiratory volumes are similar, and thus to anchor the curves at their end-inspiratory points. The data was reanalysed using the end inspiratory points to anchor the curves. Maximal curves from regular RCT were compared to maximal curves obtained when endinspiratory occlusion preceded RCT (fig. 3).

Expiratory time depends on the expiratory volume and on the expiratory flow. To correct for differences in volumes between the different manoeuvres, taped signals were transferred to a microcomputer program for further analysis. The expiratory time corrected for lung volume $(\mathrm{TE} / \mathrm{VE})$ was calculated for the expiratory flow signals for the three manoeuvres.

\section{Statistical analysis}

Mean values of $\dot{V}_{50}$ and $\dot{V}_{75}$ for the three manoeuvres were compared using analysis of variance (ANOVA), and student's paired t-test for comparison of the two manoeuvres. Mean values of $\mathrm{TE} / \mathrm{VE}$ at each compression pressure were compared using the student's paired t-test for RCT and end-inspiratory occlusion prior to $\mathrm{RCT}$, and for regular RCT and stacking prior to RCT.

\section{Results}

All the patients in our study showed a marked increase in the maximal expiratory flow ( $\operatorname{Vmax}$ ) when end-inspiratory occlusion was applied prior to chest compression. Even higher flows were obtained with expiratory clamping prior to the compression. Table 2 shows the maximal flows achieved by the three manoeuvres for each patient. The mean values \pm SD of $\dot{V}_{50}$ and $\dot{V} 75$ with regular RCT were $207 \pm 44$ and $138 \pm 59 \mathrm{ml} \cdot \mathrm{s}^{-1}$ respectively. When end-inspiratory occlusion preceded RCT, $\dot{V}_{50}$ and $\dot{V}_{75}$ by 34 and $31 \%$, respectively. When expiratory clamping preceded the compression, even higher expiratory flows resulted. $\dot{V}_{50}$ increased by $53 \%$ and 
Table 2. - Values of flow obtained by the three different techniques, measured at 50 and $75 \%$ of the expiratory volume of the RCT curve

\begin{tabular}{|c|c|c|c|c|c|c|c|c|c|c|}
\hline \multirow{3}{*}{$\begin{array}{l}\text { Patient } \\
\text { No. } \\
1\end{array}$} & \multicolumn{5}{|c|}{$\dot{\mathrm{V}} 50\left(\mathrm{ml} \cdot \mathrm{s}^{-1}\right)$} & \multicolumn{5}{|c|}{$\dot{\mathrm{V}} 75\left(\mathrm{ml} \cdot \mathrm{s}^{-1}\right)$} \\
\hline & \multirow{2}{*}{$\begin{array}{l}\text { RCT } \\
202\end{array}$} & \multicolumn{2}{|c|}{$\mathrm{EIO}+\mathrm{RCT}$} & \multicolumn{2}{|c|}{$\mathrm{EC}+\mathrm{RCT}$} & \multirow{2}{*}{$\begin{array}{c}\text { RCT } \\
177\end{array}$} & \multicolumn{2}{|c|}{$\mathrm{EIO}+\mathrm{RCT}$} & \multicolumn{2}{|c|}{$\mathrm{EC}+\mathrm{RCT}$} \\
\hline & & 254 & (26) & 298 & $(48)$ & & 200 & (13) & 203 & (15) \\
\hline 2 & 143 & 180 & (27) & 181 & (27) & 93 & 131 & (41) & 143 & (54) \\
\hline 3 & 185 & 241 & (30) & 264 & (43) & 153 & 196 & (28) & 237 & (55) \\
\hline 4 & 266 & 563 & (112) & 760 & (186) & 180 & 338 & (88) & 489 & (172) \\
\hline 5 & 197 & 246 & (25) & 261 & (33) & 153 & 177 & (16) & 199 & (30) \\
\hline 6 & 180 & 200 & (11) & 221 & (23) & 120 & 156 & (30) & 161 & (34) \\
\hline 7 & 288 & 333 & (16) & 368 & (28) & 234 & 265 & (13) & 317 & (36) \\
\hline 8 & 192 & 244 & (27) & 267 & (39) & 155 & 189 & (22) & 225 & (45) \\
\hline Mean & 207 & 283 & $(34)^{+}$ & 227 & $(53)^{+}$ & 138 & 206 & $(31)^{+}$ & 264 & $(55)^{+}$ \\
\hline SD & 44 & 144 & & 171 & & 59 & 61 & & 104 & \\
\hline
\end{tabular}

Data in parentheses are percentage of increase in flow compared to the corresponding RCT curve. RCT: rapid compression technique; EIO: end expiratory occlusion; EC: expiratory clamping; $\dot{\mathrm{V}}_{50}$ and $\dot{\mathrm{V}}_{75}$ : forced expiratory flow at $50 \%$ and $75 \%{ }^{+}: \mathrm{p}<0.05$ versus RCT only.

$\dot{V}_{75}$ by $55 \%$ in, compared to regular RCT. Thus, the greatest expiratory flows were achieved by expiratory clamping prior to the chest compression.

The curves were then anchored at their end-inspiratory points and maximal curves from regular RCT were compared to maximal curves obtained when endinspiratory occlusion preceded RCT. Table 3 shows the results of these analyses; higher flows resulted when end-inspiratory occlusion preceded the RCT. The mean \pm SD of $\dot{V}_{50}$ with regular RCT was $190 \pm 67 \mathrm{ml} \cdot \mathrm{s}^{-1}$ and increased to $235 \pm 89 \mathrm{ml} \cdot \mathrm{s}^{-1}$ when end-inspiratory occlusion preceded RCT $(\mathrm{p}<0.01)$. V75 with regular RCT was $128 \pm 47$ $\mathrm{ml} \cdot \mathrm{s}^{-1}$ and increased to $156 \pm 52 \mathrm{ml} \cdot \mathrm{s}^{-1}$ with end inspiratory occlusion prior to RCT $(\mathrm{p}<0.01)$. Thus, whichever way we anchor the curves, higher flows were obtained when end-inspiratory occlusion preceded the compression.

$\mathrm{TE}_{\mathrm{E}} / \mathrm{VE}$ measurements were made in four patients. Mean $\mathrm{Te} / \mathrm{Ve}$ for the maximal compression pressure (the pressure beyond which no further increase in flow was observed), was shortened significantly from 12.8 \pm 7.4

Table 3. - Values of flow obtained by regular RCT, and RCT following EIO, measured at 50 and $75 \%$ of the expiratory volume of the RCT curve (curves were anchored at end-expiratory volume)

\begin{tabular}{lrrlrrl}
\hline $\begin{array}{l}\text { Patient } \\
\text { No. }\end{array}$ & \multicolumn{3}{c}{$\dot{\text { Vं50 }}\left(\mathrm{ml} \cdot \mathrm{s}^{-1}\right)$} & \multicolumn{3}{c}{$\dot{\mathrm{V}} 75\left(\mathrm{ml} \cdot \mathrm{s}^{-1}\right)$} \\
\hline 1 & 208 & 272 & $(31)$ & 160 & 197 & $(23)$ \\
2 & 75 & 87 & $(16)$ & 57 & 68 & $(19)$ \\
3 & 148 & 214 & $(45)$ & 93 & 148 & $(59)$ \\
5 & 184 & 236 & $(28)$ & 120 & 149 & $(24)$ \\
6 & 174 & 181 & $(4)$ & 109 & 113 & $(4)$ \\
7 & 311 & 403 & $(30)$ & 216 & 239 & $(11)$ \\
8 & 230 & 259 & $(10)$ & 139 & 176 & $(27)$ \\
\hline Mean & 190 & 235 & & 128 & 156 & \\
SD & 67 & 89 & & 47 & 52 &
\end{tabular}

Data for patient No. 4 were unavailable for this study. Data in parentheses are percentage of increase in flow. For abbrcviations see legend to table 2 . $\mathrm{ms} \cdot \mathrm{ml}^{-1}$ with regular RCT to $10.2 \pm 5.8 \mathrm{~ms} \cdot \mathrm{ml}^{-1}$ when end inspiratory occlusion preceded RCT $(\mathrm{p}<0.01)$, and to $7.2 \pm 3.6 \mathrm{~ms} \cdot \mathrm{ml}^{-1}$ when expiratory clamping preceded RCT $(\mathrm{p}<0.01)$.

\section{Discussion}

The results of our study show that if a brief end-inspiratory occlusion precedes the expiration, flows higher than the "maximal flow" obtained by the standard RCT were achieved. Presumably, this was because the occlusion invoked a Hering-Breuer reflex that relaxed the respiratory muscles. The stacking process may invoke an even more powerful Hering-Breuer reflex, due to the higher lung volume prior to the occlusion. The higher lung volume is probably associated with increased pulmonary elastic recoil pressure, which increases the expiratory flow $[16,17]$. The end result is a substantial increase in flow during the forced expiration.

We had difficulties in making numerical measurements of changes in flow rate with the different manoeuvres because of uncertainty about the volume axis. In the infants examined, FRC was quite variable, and this is apparent in other studies where multiple, rather than single "representative", tidal volume loops are shown. Initially, we assumed, as others have done using this technique, that the lung volume at the end of the compression was $\mathrm{RV}$; therefore, we anchored the curves at end-expiratory points. We consistently noted, as the data of others have shown [1,10,21-24], that the difference between FRC and RV is small, i.e. there is a very small expiratory reserve volume and it is unlikely that true $\mathrm{RV}$ is reached. Careful examination of volume/time traces showed that the end-expiratory volume after a compression following end-inspiratory occlusion was generally lower than after the standard compression. The end-expiratory volume is probably determined by the sharp decrease in compliance below FRC, and possibly by active expiratory braking by the muscles of inspiration. Our data suggest that RV is not reached by 
standard RCT and that active braking may play a role in determining the end-expiratory point. In contrast, after stacking, the end-expiratory volume was generally higher than the preceding end expiratory volume, and it took several breaths to return to the original volume. This suggests that volume was recruited during the process of stacking, and the process of return to the initial volume is not immediate. Thus, both the occlusion and the stacking techniques increase flow throughout the volume range, indicating that the standard RCT does not generate a flow-volume curve determined by flow limitation.

The basic assumption upon which the RCT technique rests is that flow is limited by the intrinsic properties of the lungs. Classically, the pressure at which flow limitation occurs has to be defined with isovolume pressureflow curves, where further increases in pleural pressure produce no further increase in flow [13]. Because of the difficulty in measuring accurate isovolume pressure-flow curves in sedated infants, criteria to demonstrate flow limitation have been modified by previous investigators $[1,21]$. Flow limitation is generally considered to have occurred if increases in compression pressure no longer result in increases in the flow rate achieved by compression.

There are assumptions required for this to be true. These are that the pressure applied is transmitted effectively to the pleural surface, and that the chest wall and the respiratory muscles are relaxed. Under these assumptions, the maximal flow obtained by RCT reflects flow limitation by the intrinsic properties of the lung. The first of these assumptions is safe to make, provided that care is taken in the design and fit of the compression jackets. As for the second assumption, several studies have suggested that relaxation of the thorax did not occur. Hoskyns et al. [10] and CASTILE et al. [11] studied the changes in pleural pressure during RCT by measuring oesophageal pressure. They noted a fall in oesophageal pressure immediately after the squeeze. KusAKAwA et al. [25] also demonstrated in Rhesus monkeys that muscular activity is present during RCT. Higher flows were achieved after the animals were paralysed, and then compressed. This study can be criticized because of the potential effects of anaesthesia, and species differences. In other studies, higher expiratory flows have been observed in newborns when the compression pressure was applied in mid-expiration as opposed to endinspration $[10,26]$.

If flow is limited by the intrinsic properties of the lung, timing of the RCT should not increase the maximal flow. RATJEN et al. [24] had an ingenious method of demonstrating flow limitation by superimposing oscillatory static cuff pressure during the squeeze, whilst expiratory flow was measured. They demonstrated absence of associated oscillations when compression yielded maximal flow. They concluded that flow limitation had been achieved. In fact, this may not demonstrate flow limitation, but does demonstrate that maximal compression pressure has been achieved. In addition, they noticed that in the normal infants the oscillations reappeared prior to the transition from expiration to inspiration. They could not explain this phenomenon, which occurred close to the volume where $\dot{V} \max$ is determined. If we assume that the respiratory muscles contract and resist the compression, a relaxation prior to the next inspiration may lead to the reappearance of the oscillations and, thus, provide further indirect proof that the flow limitation they achieved was not true flow limitation. All of these findings support our conclusion that by the rapid chest compression technique, flow is not limited only by the intrinsic properties of the lungs, but also by reflexes elicited by sudden and rapid chest and abdomen compression that induce expiratory braking.

Our interpretation of these findings is that sudden chest compression invokes reflex expiratory braking by laryngeal adduction, inspiratory muscle activity, or both. There is extensive evidence that expiratory airflow is actively regulated by a feedback control system involving both the larynx and inspiratory muscles [27, 28]. REMMERS and BARTLETT [29], in unanaesthetized cats, showed that sudden opening of a previously prepared tracheostomy for a single expiration elicits a vagally mediated, co-ordinated response in the respiratory muscles, effectively braking expiratory air flow. HARDING [30] also demonstrated glottic adduction in foetal lambs when the chest wall was compressed. In addition, our data on the expiratory time normalized for the expiratory volume (TE/VE) demonstrate that $\mathrm{Te} / \mathrm{VE}$ is significantly shorter after end-inspiratory occlusion or stacking prior to the compression. This suggests that a marked reduction in expiratory braking occurs with this techniques. We believe that these reflexes are activated in infants during rapid chest compression. In some children, an audible grunt associated with laryngeal adduction is noted during the compression. Inspiratory muscle activity is sometimes also apparent as visible contraction of the sternocleidomastoid during the compression.

The present finding of increased flow and decreased braking, in conjunction with the evidence of inspiratory effort from other studies measuring oesophageal pressure $[10,11]$, and the results after muscle paralysis in monkeys [25], constitutes strong evidence that, during the standard RCT, flow is not limited by the intrinsic properties of the lung, but by expiratory muscle braking. Therefore, considerable care must be exercised in interpreting the effects of agents which produce changes in the "squeezed" partial flow volume curve.

Application of rapid chest compression after expiratory clamping, as described in this manuscript, is of particular interest. This technique enables forced expiratory flow volume curves to be generatrated from a volume close to total lung capacity. Further investigation of this technique is required before it can be routinely applied. In our experience, no side-effects were observed, and, furthermore, the maximal compression pressure was similar to that achieved during the regular RCTs. There is still uncertainty whether the flow-volume curve generated after end-inspiratory occlusion or after stacking represent flow limitation. To prove this would require measuring isovolume pressure flow curves using oesophageal pressure. However, it is clear that higher flow rates can be achieved after a Hering-Breuer reflex, and this, in our opinion, should be routinely performed 
before a squeeze, although, there is no guarantee that this produces a complete relaxation, even after stacking. Of particular concern is the evidence of ENGLAND et al. [31], in puppies, that the Hering-Breuer reflex does not abolish thyroarytenoid activity, although this activity is markedly reduced by chloral hydrate.

We included in the study only sick patients, who were sedated and had pulmonary function tests as part of their evaluation of their disease. We felt it would be unethical to sedate normal children for such studies. However, every patient had measurements with the three techniques, the standard technique as baseline, and then the two other techniques. There was no comparison made between patients, but between measurements in each patient. No change in flows is expected if flow limitation has occurred. If this was the case than a legitimate argument would have been to test normals. Nonetheless, it is possible that in infants with pulmonary conditions which cause them to breathe close to their intrinsic flow limitation, the maximum flow volume curve may reflect real flow limitation. The corollary, however, is that this possibility seems to be unlikely in infants who are relatively well. Further studies of larger numbers of patients and of normal infants are needed to answer these questions.

Acknowledgements: The authors thank H. Frndova for technical help and J. Chay for secretarial assistance.

\section{References}

1. Adler SM, Wohl MEB. Flow-volume relationship at low lung volumes in healthy term newborn infants. Pediatrics 1978; 61: 636-640.

2. Tepper RS, Morgan WJ, Cota K, Wright A, Taussig LM. Physiologic growth and development of the lung during the first year of life. Am Rev Respir Dis 1986; 134: 513-519.

3. Hughes DM, Lesouef PN, Landau LI. Effect of salbutamol on respiratory mechanics in bronchiolitis. Pediatr Res 1987; 22: 83-86.

4. Beardsmore CS, Bar-Yishay E, Maayan C, Yahav Y, Katznelson D, Godfrey S. Lung function in infants with cystic fibrosis. Thorax 1988; 43: 545-551.

5. Hiatt P, Eigen H, Yu P, Tepper RS. Bronchodilator responsiveness in infants and young children with cystic fibrosis. Am Rev Respir Dis 1988; 137: 119-122.

6. Morgan WJ, Geller DE, Tepper RS, Taussig LM. Partial expiratory flow-volume curves in infants and young children. Pediatr Pulmonol 1988; 5: 232-243.

7. Maclean D, Drummond G, Macpherson C, McLaren G, Prescott R. Maximum expiratory airflow during chest physiotherapy on ventilated patients before and after the application of an abdominal binder. Intensive Care Med 1989; 15: 396-399.

8. Montgomery GL, Tepper RS. Changes in airway reactivity with age in normal infants and young children. $\mathrm{Am}$ Rev Respir Dis 1990; 142: 1372-1376.

9. Martinez FD, Taussig MD, Morgan WJ. Infants with upper respiratory illnesses have significant reductions in maximal expiratory flow. Pediatr Pulmonol 1990; 9: 91-95.

10. Hoskyns EW, Milner AD, Hopkin IF. Validity of forced expiratory flow-volume loops in neonates. Arch Dis Child 1987; 62: 895-900.

11. Castile RG, Laflamme MJ, Dorkin HL, MacKinnon BL,
Frantz ID. Changes in intrathoracic pressure during partial expiratory flow-volume manoeuvres in infants (Abstract). Pediatr Res 1988; 23: 2160A.

12. England SJ. Current techniques for assessing pulmonary function in the newborn and infant: advantages and limitations. Pediatr Pulmonol 1988; 4: 48-53.

13. Fry DL, Hyatt RE. Pulmonary mechanics: a unified analysis of the relationship between pressure, volume and gas flow in the lungs of normal and diseased subjects. Am J Med 1960; 29: 672-689.

14. Cross KW, Klauss M, Tooley WH, Weisser K. The response of the newborn baby to inflation of the lung. J Physiol 1960; 151: 551-565.

15. Grunstein MM, Springer C, Godfrey S, et al. Expiratory volume clamping: a new method to assess respiratory mechanics in sedated infants. J Appl Physiol 1987; 62: 2107-2114.

16. Mansell AL, Bryan AC, Levison H. Relationship of lung recoil to lung volume and maximum expiratory flow in normal children. J Appl Physiol 1977; 42: 817-823.

17. Mead J, Turner JM, Macklem PT, Little JB. Significance of the relationship between lung recoil and maximum expiratory flow. J Appl Physiol 1967; 22: 95-108.

18. Kerem E, Bentur L, England S, et al. Sequential pulmonary function measurements during treatment of infantile chronic interstitial pneumonitis. J Pediatr 1990; 116: 61-67.

19. Kosch PC, Stark AR. Dynamic maintenance of endexpiratory lung volume in full-term infants. $J$ Appl Physiol: Respirat Environ Exercise Physiol 1984; 57: 1126-1133.

20. Mortola JP, Milic-Emili J, Noworaj A, Smith B, Fox G, Weeks S. Muscle pressure and flow during expiration in infants. Am Rev Repir Dis 1984; 129: 49-53.

21. Taussig LM, Landau LI, Godfrey S, Arad I. Determinants of forced expiratory flows in newborn infants. $J \mathrm{Appl}$ Physiol: Respirat Environ Exercise Physiol 1982; 53: $1220-1227$.

22. Godfrey S, Bar-Yishay E, Arad I, Landau LI, Taussig LM. Flow-volume curves in infants lung disease. Pediatrics 1983; 72: 517-522.

23. Lesouef PN, Hughes DM, Landau LI. Shape of forced expiratory flow-volume curves in infants. Am Rev Respir Dis 1988; 138: 590-597.

24. Ratjen F, Zinman R, Wohl MEB. A new technique to demonstrate flow limitation in partial expiratory flowvolume curves in infants. J Appl Physiol 1989; 67: 1662-1669.

25. Kusakawa I, Motomyama EK, Moumbourlis AC, Lee Foon W, Walczak S. Absence of flow limitation in partial expiratory flow volume curves (PEFVCs) by thoracoabdominal compression (TAC) in healthy Rhesus monkeys. (Abstract) Am Rev Respir Dis 1988; 137:A339.

26. Silverman MA, Predville A, Green S. Partial expira tory flow-volume curves in infanct: technical aspects. Bull Eur Physiopathol Respir 1986; 22: 257-262.

27. Rattenborg C. Laryngeal regulation of respiriation. Acta Anaesthesiol Scand 1961; 5: 129-140.

28. Bartlett D, Remmers JE, Gautier H. Laryngeal regulation of respiratory airflow. Respir Physiol 1973; 18: 194-204.

29. Remmers JE, Bartlet D. Reflex control of expiratory airflow and duration. J Appl Physiol 1977; 42: 80-87.

30. Harding R. State-related and developmental changes in laryngeal function. Sleep 1980; 3: 307-322.

31. England SJ, Keng G, Stogryn HAF. Laryngeal muscle and diaphragmatic activities in conscious dog pups. Respir Physiol 1985; 95-108. 